\title{
Impact of blood hypercoagulability on in vitro fertilization outcomes: a prospective longitudinal observational study
}

Grigoris T. Gerotziafas ${ }^{1,2^{*}}$, Patrick Van Dreden ${ }^{3}$, Emmanuelle Mathieu d'Argent $^{4}$, Eleftheria Lefkou', Matthieu Grusse ${ }^{3}$, Marjorie Comtet ${ }^{4}$, Rabiatou Sangare ${ }^{3}$, Hela Ketatni ${ }^{2}$, Annette K. Larsen ${ }^{1}$ and Ismail Elalamy ${ }^{1,2}$

\begin{abstract}
Background: Blood coagulation plays a crucial role in the blastocyst implantation process and its alteration may be related to in vitro fertilization (IVF) failure. We conducted a prospective observational longitudinal study in women eligible for IVF to explore the association between alterations of coagulation with the IVF outcome and to identify the biomarkers of hypercoagulability which are related with this outcome.

Methods: Thirty-eight women eligible for IVF (IVF-group) and 30 healthy, age-matched women (control group) were included. In the IVF-group, blood was collected at baseline, 5-8 days after administration of gonadotropin-releasing hormone agonist $(\mathrm{GnRH})$, before and two weeks after administration of human follicular stimulating hormone (FSH). Pregnancy was monitored by measurement of $\beta H C G$ performed 15 days after embryo transfer. Thrombin generation (TG), minimal tissue factor-triggered whole blood thromboelastometry $\left(\right.$ ROTEM $\left.^{\circledR}\right)$, procoagulant phospholipid clotting time (Procoag-PPL ${ }^{\circledR}$ ), thrombomodulin (TMa), tissue factor activity (TFa), factor VIII (FVIII), factor von Willebrand (FVW), D-Dimers and fibrinogen were assessed at each time point.

Results: Positive IVF occurred in 15 women (40\%). At baseline, the IVF-group showed significantly increased TG, TFa and TMa and significantly shorter Procoag-PPL versus the control group. After initiation of hormone treatment TG was significantly higher in the IVF-positive as compared to the IVF-negative group. At all studied points, the Procoag-PPL was significantly shorter and the levels of TFa were significantly higher in the IVF-negative group compared to the IVF-positive one. The D-Dimers were higher in the IVF negative as compared to IVF positive group. Multivariate analysis retained the Procoag-PPL and TG as predictors for the IVF outcome.

Conclusions: Diagnosis of women with hypercoagulability and their stratification to risk of IVF failure using a model based on the Procoag-PPL and TG is a feasible strategy for the optimization of IVF efficiency that needs to be validated in prospective trials.
\end{abstract}

Keywords: Tissue factor, Blood coagulation tests, Thrombin generation, In vitro fertilization, Hypercoagulability

\footnotetext{
*Correspondence: grigorios.gerotziafas@aphp.fr

'Cancer Biology and Therapeutics, Centre de Recherche Saint-Antoine, Institut National de la Santé et de la Recherche Médicale (INSERM) U938 and Université Pierre et Marie Curie (UPMC), Sorbonne Universities, Paris, France

2Service d'Hématologie Biologique, Hôpital Tenon, Hôpitaux Universitaires Est Parisien, Assistance Publique Hôpitaux de Paris, 4, rue de la Chine, Paris

Cedex 20, France

Full list of author information is available at the end of the article
} 


\section{Background}

The link between blood hypercoagulability and infertility or in vitro fertilization (IVF) failure is a puzzling issue. Hypercoagulability could be intrinsic or caused by the hormone treatment preceding the IVF procedure [1-6]. Tissue factor is the major trigger of blood coagulation and thrombin generation is the ultimate step that leads to fibrin formation. The activation of coagulation induced by tissue factor (TF) expressed by perivascular decidualized human endometrial stromal cells is an essential part of the mechanism that favors blastocyst implantation and prevents peri-implantational hemorrhage during endovascular trophoblast invasion. Thrombin generation is required for cell proliferation, neoangiogenesis, trophoblast invasion and remodeling of the spiral arteries and arterioles [7-9]. Thus, the shift of blood coagulation equilibrium towards locally enhancement of thrombin generation may have some beneficial effects for a positive outcome of IVF. On the other hand, in infertile women activation or dysfunction of platelets, endothelial cells and monocytes has been observed [10,11].

Newer laboratory assays allow the assessment of global blood coagulation and clot formation process. Among them, the Calibrated Automated Thrombogram ${ }^{\circ}$ and the minimal TF-triggered whole blood thromboelastometry allow the evaluation of thrombin generation and clot formation processes [12-14]. The measurement of the procoagulant phospholipid dependent clotting time (Procoag-PPL ${ }^{\circ}$ ) reflects the plasma concentration of procoagulant membrane vesicles of cellular origin $[15,16]$. Biomarkers of endothelial cell activation such as thrombomodulin activity (TMa) and TF activity (TFa) measured in plasma offer information on the status of the endothelial cells at the vasculature.

The aim of the present prospective, observational longitudinal study was to identify biomarkers of hypercoagulability which could have some predictive value for the IVF outcome. Thrombin generation, clot formation kinetics and molecular biomarkers of cellular hypercoagulability were assessed at women eligible for IVF at baseline (before any hormone treatment administration), at the downregulation phase of the menstrual cycle and after ovarian stimulation. Biochemical diagnosis of pregnancy was the end-point of the study.

\section{Methods}

\section{Study design and participants}

A monocentric prospective, non-interventional cohort study was designed. From June 2014 to June 2015 blood samples were obtained from 38 women eligible for IVF (IVF-group). Women were recruited at the baseline consultation and then they were followed until pregnancy test was performed. Biochemical diagnosis of pregnancy was the end-point of the study. According to the levels of $\beta$-chorionic gonadotropin ( $\beta \mathrm{HCG}$ ) women were stratified into two subgroups: IVF-positive if $\beta$ HCG levels were higher than $100 \mathrm{IU} / \mathrm{L}$ and IVF-negative if ( $\beta$ HCG) levels were equal or lower than $100 \mathrm{IU} / \mathrm{L}$. The evolution of the pregnancy was not recorded.

The control group consisted of 30 healthy, age-matched women, without any known hereditary or acquired thrombophilic alteration or personal history of thrombotic or bleeding disorder who had undergone at least one uneventful physically conceived pregnancy and without any personal history of miscarriage. The protocol of the study was in accordance with the commitment of the Helsinki declaration and was approved by the institutional ethics committee. All subjects provided informed written consent before inclusion in the study.

\section{Inclusion criteria}

Women were eligible for IVF according to established selection criteria applied in our institution. All women had full blood count, platelet count, prothrombin time, activated partial thromboplastin time, fibrinogen, renal and liver function within the normal range.

\section{Exclusion criteria}

Women younger than 18 years or older than 45 years, weight less than $50 \mathrm{~kg}$ or more than $100 \mathrm{~kg}$, with a personal or family history of venous thromboembolism (VTE) or hemorrhagic syndromes, known hereditary or acquired thrombophilia, active anticoagulant or antiplatelet treatment or use of these agents during the last 30 days before inclusion, hospitalization for any reason within the previous 3 months, abnormal full blood count or platelet count and ongoing cardiovascular, renal or liver disease, malignancy, or arterial hypertension, known systematic or chronic disease (autoimmune syndrome, heart disease, severe or uncontrolled thyroid disease or HIV infection), treatment with non-steroid anti-inflammatory drugs within the last 10 days before inclusion, ovarian insufficiency ( $\mathrm{FSH}>9$ IU/ $\mathrm{ml}$ and/or number of antral follicles $<8$ ) or polycystic ovary syndrome (defined according to the Rotterdam criteria).

\section{Hormone treatment for the artificial reproductive technique}

Estrogen production was first down-regulated to induce controlled ovarian stimulation. Three different protocols of down regulation were used: a long gonadotropinreleasing hormone $(\mathrm{GnRH})$ agonist or a short agonist or an antagonist. Ovarian stimulation was done with recombinant human follicular stimulating hormone (FSH) at doses ranging from 75 IU to 450 IU per day depending on age, body mass index (BMI), antral follicle count, size and number of follicles and estradiol levels (E2). This stimulation was initiated once pituitary desensitization had been achieved (E2 level $<50 \mathrm{pg} / \mathrm{mL}$ ). The response 
was followed by E2 measurement six days later and by ultrasound scanning of the ovarian follicles at days 9-10 after the first FSH injection, and repeated when necessary. Transvaginal oocyte retrieval was scheduled 35 to $36 \mathrm{~h}$ after human recombinant chorion gonadotrophin (hCG) injection and embryo transfer was performed 2-3 days later. On day 2, individually cultured embryos were evaluated on the basis of the number of blastomeres, blastomere size, fragmentation rate and presence of multinucleated blastomeres. Therefore, the ovocytes were retrieved 10 to 14 days after starting the stimulation with the FSH.

\section{Outcomes}

Achievement of biochemical pregnancy was the outcome of the study. Pregnancy was controlled by quantitative measurement of $\beta$ HCG 15 days after embryo transfer.

\section{Blood sampling}

Blood samples were collected before the administration of any hormone treatment (T0) and during the IVF procedure as follows: at the maximal down-regulation of the menstrual cycle; between the $5^{\text {th }}$ and $8^{\text {th }}$ day from the administration of the GnRH agonist (T1); at maximal stimulation after treatment by FSH and before hCG injection (T2) and two weeks after gonadotropin-releasing hormone $(\mathrm{GnRH})$ injection (T3). Blood samples were obtained by atraumatic puncture of the antecubital vein, using a 20-gauge needle without tourniquet, into siliconized vacutainer tubes containing $0.105 \mathrm{~mol} / \mathrm{L}$ trisodium citrate; $1 / 9 \mathrm{v} / \mathrm{v}$ (Becton and Dickinson, France). Platelet-poor plasma (PPP) was obtained by double centrifugation at $2000 \mathrm{~g}$ for $20 \mathrm{~min}$ at room temperature and plasma aliquots were stored at $-80{ }^{\circ} \mathrm{C}$ until assayed. Samples were assessed within two weeks after collection. Thromboelastometry was carried out with fresh whole blood.

\section{Molecular and functional analysis}

Thrombin generation assay. Thrombin generation in plasma was assessed using the Calibrated Automated Thrombogram assay $\left(\mathrm{CAT}^{\circ}\right.$, Diagnostica Stago, Asnières France) according to manufacturers' instructions, in the presence of optimal concentrations of TF ( $5 \mathrm{pM})$ and procoagulant phospholipids $(4 \mu \mathrm{M})$ using the PPPReagent ${ }^{\circ}$. Assay's performance has been published elsewhere $[12,17]$.

Minimal TF-triggered whole blood thromboelastometry (min TF-WB TEM) was assessed in citrated whole blood, on the ROTEM $^{\circ}$ instrument $\left(\mathrm{TEM}^{\circ}\right.$, Munich, Germany). Thromboelastometry was performed at $37^{\circ} \mathrm{C}$ in citrated fresh whole blood within $30 \mathrm{~min}$ after veinipuncture using $5 \mathrm{pM}$ of TF as described elsewhere [18]. The following parameters of the thromboelastometric trace were analyzed: (a) Clotting time (CT, in sec): time from the start of the sample run to the point of first significant clot appearance corresponding to an amplitude of $2 \mathrm{~mm}$, (b) Clot formation time (CFT, in sec): time from CT until the level of clot firmness reaches an arbitrary value of $20 \mathrm{~mm}$, (c) $\alpha$ angle (degree): measurement of clot development kinetics, (d) Maximum clot firmness (MCF in $\mathrm{mm}$ ): the maximum vertical amplitude of the thromboelastogram.

Procoagulant phospholipid-dependent clotting time (Proag-PPL) was measured with STA Procoag-PPL, (Diagnostica Stago, Asnières, France) according to the manufacturer's instructions as described elsewhere. The inter- and intra-assay coefficients of variation were 3 and $4 \%$ respectively.

Thrombomodulin activity. Plasma levels of thrombomodulin activity (TMa) were measured with a functional test on the STA-R analyzer (Diagnostica Stago, Asnières, France) as described elsewhere [19]. The inter- and intraassay coefficients of variation were 5 and $6 \%$ respectively.

Specific TF activity. Tissue Factor activity (TFa) in PPP was measured with a clotting-based assay as previously described [20,21]. The inter- and intra-assay coefficients of variation were $7 \%$ and $5 \%$ respectively. The levels of, FVIII, $\mathrm{FvW}, \mathrm{D}$-Dimers and fibrinogen were measured with conventional assays according to the manufacturer's instructions (Diagnostica Stago, Asnières, France).

\section{Statistical analysis}

The calculation of the sample size was based on the minimum number of patients required for a significant power for the detection of differences (a) between the IVF and control group, (b) at the IVF at the studied time points, (c) between IVF positive and IVF negative groups. The minimum sample size of 27 individuals for each group (IVF and control as well as IVF at each time point) was defined to warrant a two-tail significance at the limit of $5 \%$ and a prediction power of $95 \%$ with a two-sided $\alpha$ level of 0.05. Regarding the sub-group analysis (IVF positive and IVF negative) the minimum size of 15 patients for each group warrants two-tail significance at the limit of $5 \%$ and a prediction power of $85 \%$ with a two-sided $\alpha$ level of 0.05 .

Special effort and attention was given to avoid missing values. The data are presented as mean $\pm \mathrm{sd}$. The MannWhitney test for independent samples was used for the comparisons of the studied parameters between the IVF and the control group and between the IVF-positive and IVF-negative group. Non-parametric Wilcoxon test for related samples and ANOVA test were applied to compare changes in variables at the studied time points during the observation period. Pearsons' test was applied to control correlation between thrombogram parameters and studied blood coagulation variables. Dichotomous variables were compared with $\chi^{2}$ test. The Upper Normal Limit (UNL) and the Lower Normal Limit (LNL) for each parameter of 
the studied variables were defined in the control group as follows: $\mathrm{UNL}=$ mean $+2 \mathrm{SD}$, and $\mathrm{LNL}:=$ mean $-2 \mathrm{SD}$. The UNL and LNL of the studied biomarkers were defined in the control group and were compared to the corresponding normal reference range used by our laboratory. The normal ranges have been established according to the requirements for the good quality of laboratory practice by performing the tests in healthy individuals representative of the general population regarding age, sex, ethnicity, BMI. Two-sided values of $p<0.05$ were considered as statistically significant.

The model development started by defining the positive diagnosis of pregnancy (if $\beta H C G$ levels were equal or lower than $100 \mathrm{IU} / \mathrm{L}$ ) as the dependent variable. The first step consisted of the univariate analysis in order to identify the variables associated with positive pregnancy. The selection of independent variables (which are the biomarkers of hypercoagulability) was done at the level of 5\% using the stepwise procedure. The multivariable linear regression model was used to explore the effect of the independent variables on pregnancy outcome. The variables, found to be significant in the univariate analysis $(p<0.05)$ were included in the multivariate analysis. The variable with the highest $\mathrm{p}$ value was excluded from the model. The discrimination capacity of the model was tested with receiver operating characteristics (ROC) analysis and the area under the curve (AUC) was calculated for the quantification of the discrimination capacity of the model. The SPSS statistical software package (Chicago inc 6.1) was used for statistical analysis. Values are mean \pm standard deviation.

\section{Results}

In total 38 women were eligible for the study and completed the follow up. The clinical and demographic characteristics of the studied groups are shown in Table 1. Positive IVF occurred in 15 women (40\%) and negative in 23 (60\%). The demographic characteristics and the indication for IVF were similar in the IVF-positive and IVF-negative group. None of the women included in the IVF and the control group had hypertension, hyperlipidemia or diabetes. None of the women suffered thromboembolic complication.

The UNL and LNL of the studied biomarkers in the control group were not significantly different as compared to the respective normal reference ranges used in our laboratory (Table 2).

\section{Baseline profile}

At T0, the IVF-group showed significantly increased thrombin generation (marked by shorter lag-time and ttPeak and higher ETP, Peak and MRI), and significantly shorter Procoag-PPL as compared to the control group. At least one thrombogram parameter was higher than
Table 1 Demographic and clinical characteristics of women eligible for IVF and in subgroups stratified according to the IVF outcome

\begin{tabular}{|c|c|c|c|c|}
\hline Characteristics & $\begin{array}{l}\text { IVF group } \\
(n=38)\end{array}$ & $\begin{array}{l}\text { IVF-positive } \\
(n=15)\end{array}$ & $\begin{array}{l}\text { IVF-negative } \\
(n=23)\end{array}$ & $\begin{array}{l}\text { Control group } \\
(n=30)\end{array}$ \\
\hline \multicolumn{5}{|l|}{ Demographics } \\
\hline Age (years) & $33.7 \pm 3.5$ & $33.7 \pm 3.5$ & $33.7 \pm 3.5$ & $32.2 \pm 2.2$ \\
\hline $\mathrm{BMI}$ & $22.8 \pm 2.9$ & $22.8 \pm 2.9$ & $22.8 \pm 2.9$ & $23.8 \pm 2.1$ \\
\hline \multicolumn{5}{|l|}{ Indication for IVF } \\
\hline endometriosis & 2 & 1 & 1 & - \\
\hline idiopathic & 17 & 17 & 14 & - \\
\hline $\begin{array}{l}\text { ovarian } \\
\text { insufficiency }\end{array}$ & 1 & 1 & & - \\
\hline tubal & 4 & 2 & 2 & - \\
\hline male origin & 14 & 7 & 7 & - \\
\hline \multicolumn{5}{|c|}{ Previous pregnancy } \\
\hline 0 & 31 & 15 & 16 & - \\
\hline 1 & 4 & 3 & 1 & 10 \\
\hline 2 & 3 & 1 & 2 & 20 \\
\hline \multicolumn{5}{|c|}{ Previous miscarriages } \\
\hline 0 & 36 & 17 & 19 & 30 \\
\hline 1 & 2 & 1 & 1 & 0 \\
\hline \multicolumn{5}{|c|}{ Cardiovascular risk factors } \\
\hline $\begin{array}{l}\text { Current } \\
\text { smokers }\end{array}$ & $7(18 \%)$ & $3(10 \%)$ & $4(13 \%)$ & $8(27 \%)$ \\
\hline
\end{tabular}

the UNL in $50 \%$ of women and lower than the LNL in $14 \%$. The IVF group also had significantly higher levels of TFa, TMa. The levels of FVIII, FvW, D-Dimers and fibrinogen were not significantly different between the IVF-group and the control group (Table 2).

\section{Effect of down-regulation of the menstrual cycle}

At T1, thrombin generation, Procoag-PPL, TFa, TMa, FVIII, fibrinogen and D-Dimers were not significantly different as compared to T0. The levels of FvW significantly increased as compared to T0 (Table 2). Women with ETP, Peak or MRI above the UNL at T0 did not show any significant differences at $\mathrm{T} 1$.

\section{Effect of ovarian stimulation}

At T2, Peak, MRI and the levels of FVIII and D-Dimers were significantly increased as compared to $\mathrm{T} 1$ (Table 2). In contrast the Procoag-PPL and the levels of TFa, TMa and FvW did not vary significantly as compared to $\mathrm{T} 1$.

\section{Effect of GnRH treatment}

At T3, thrombin generation was not significantly different as compared to T2. The Procoag-PPL, TFa and TMa, FvW, and fibrinogen remained at the same levels 


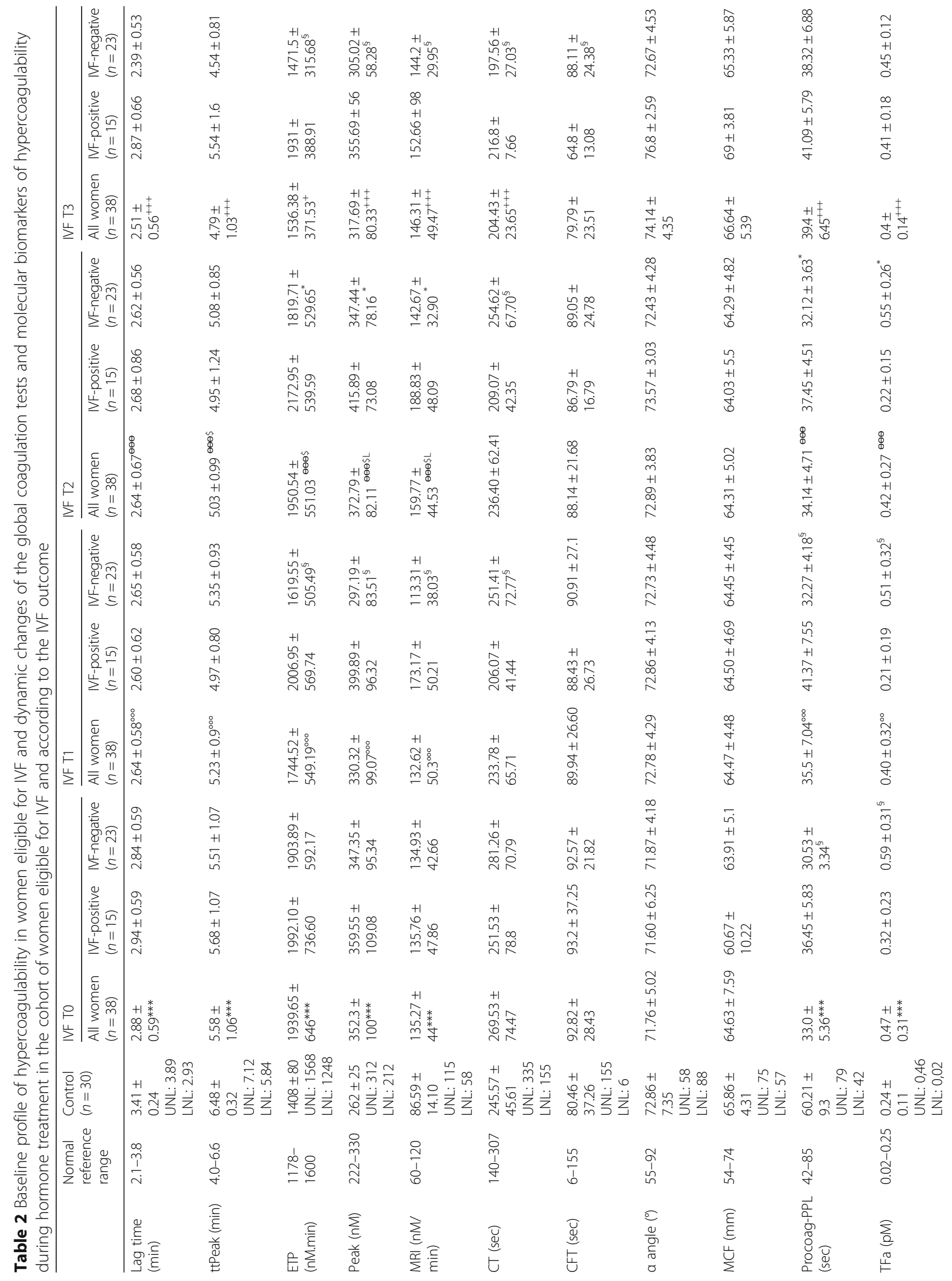




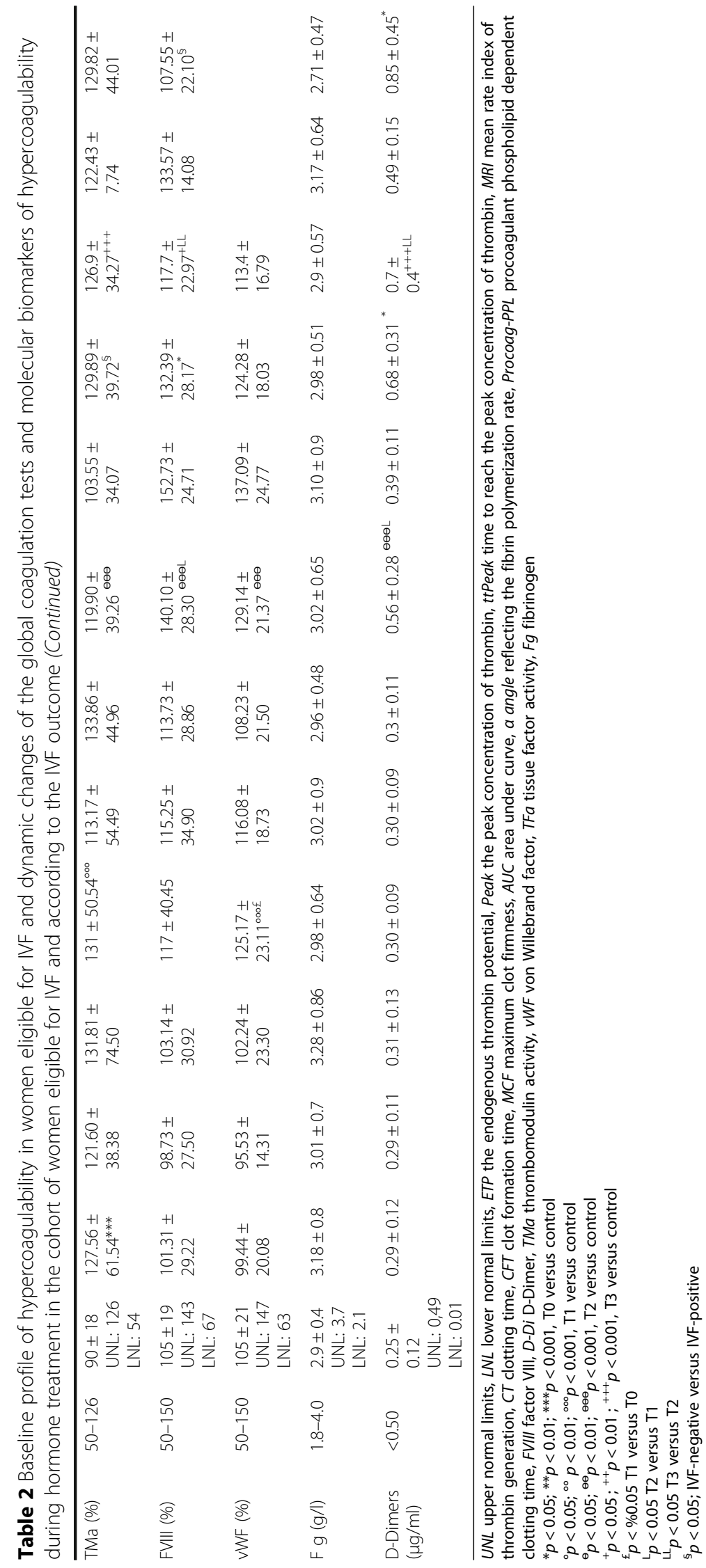


as in T2. The levels of FVIII significantly decreased at T3 as compare to T2. The levels of D-Dimers significantly increased as compared to T2 (Table 2).

At all studied time points the parameters of thromboelastometry were not significantly different between the IVF-group and the control group (Table 2).

\section{Blood hypercoagulability and IVF outcome}

At T2 and T3 the ETP, Peak and MRI were significantly higher in the IVF-positive as compared to the IVF-negative group. At T0, T1 and T2 the Procoag-PPL was significantly shorter in the IVF-negative group compared to the IVFpositive group. At all time points except T3, the levels of TFa were significantly higher in the IVF-negative group as compared to the IVF-positive group. The levels of TMa were significantly higher in the IVF-negative group as compared to the IVF-positive group only at T2. At T2 and T3 FVIII levels were significantly lower in IVF negative as compared to IVF positive. At T2 and T3, D-Dimers were significantly higher in the IVF-negative as compared to the IVF-positive group. At T1 and T2, the CT was significantly shorter in the IVF-positive group as compared to the IVFnegative. (Table 2).

The Procoag-PPL was inversely correlated with the lagtime $(r=-0.304 ; p=0.013)$, ETP $(r=-0,4 ; p=0.001)$ and MRI $(r=-0.380 ; p=0.002)$ as well as with the TFa $(r=$ $-0.399 ; p=0.001)$. Thrombomodulin was inversely correlated with $\operatorname{ETP}(r=-0.346 ; p=0.019)$.

Univariate analysis showed the following biomarkers to have a significant correlation with the positive outcome of IVF: at T0, the FvW; at T1 the ETP, Peak, MRI, Procoag-PPL and TFa; at T2, the ETP, Peak, MRI, Procoag-PPL, TFa and D-Dimers (Table 3).

There was a strong association between IVF-positive outcome and Procoag-PPL longer than $31.1 \mathrm{sec}$. Women who had Procoag-PPL between 31.1 and $54.9 \mathrm{sec}$ had 24-fold higher probability for pregnancy than the women with Procoag-PPL values lower than 31.1 sec.

Multivariate analysis for the identification of biomarkers which are correlated with a positive outcome of IVF retained the Procoag-PPL and MRI of thrombin generation. Multivariate analysis applied at the T1 led to the construction of a prediction model including the ProcoagPPL and the MRI according to the equation:

$$
Y=(0.043 * M R I) *(0.45 * \text { Procoag }-P P L)
$$

The ROC curve showed a very good specificity and sensitivity of the model for the prediction of pregnancy since the area under the curve was 0.99 (Fig. 1).

\section{Discussion}

The present prospective longitudinal observational study demonstrates that at baseline, women eligible for IVF present blood hypercoagulability which is characterized by significant increase of platelet and endothelial cell activation biomarkers. The baseline state of cellular hypercoagulability, which persisted practically unchanged during the period of hormone treatment administration for IVF, was consisted of significantly shortening of Procoag-PPL clotting time. This test is correlated with increased concentration of procoagulant microparticles derived from platelets or other cells $[22,23]$. The levels of TFa and TMa, at baseline and during hormone treatment, were also significantly increased as compared to age-matched women with naturally occurring uneventful pregnancies. The TFa and TMa are biomarkers of endothelial cell or platelet activation [24-26]. In addition, increased TFa levels in plasma is a marker of monocyte activation [27]. The Procoag-PPL, TFa and TMa levels were not significantly modified during treatment for estrogen down-regulation and ovarian stimulation indicating that the shift towards cellular hypercoagulability observed at baseline was not correlated with hormone variations. The data from the present study are in accordance with those recently published by Olausson et al. which demonstrate that platelet, endothelial and monocytederived microparticles and inflammation biomarkers are significantly increased in women undergoing IVF [28]. Thrombin generation was also significantly enhanced but the baseline levels of FVIII, FvW, D-Dimers and fibrinogen were similar to those observed in the control group, confirming previous studies [4]. To the best of our knowledge, this is the first study showing that infertility is linked to a systemic cell activation that offers procoagulant substances, mainly endothelial cells and platelets. This concept is supported by recent studies reporting that increased levels of plasminogen activator inhibitor 1 (PAI-1), thrombin activatable fibrinolysis inhibitor (TAFI) or tissue factor pathway inhibitor (TFPI), which are synthesized and secreted by activated endothelial cells are related with infertility and IVF failure [29-32].

Furthermore, the present study showed that short Procoag-PPL clotting time as well as increased TFa and TMa levels are independent risk factors for IVF failure. The implication of high levels of TF and procoagulant microparticles in the pathogenesis of infertility, IVF failure and vascular complications during pregnancy, such as recurrent first trimester miscarriage, fetal loss, stillbirth, early and severe pre-eclampsia or prematurity has already been reported by others (reviewed in [33, 34]). Herein, we demonstrate for a first time that the shortened Procoag-PPL associated with the mean rate index (MRI) of the propagation phase of thrombin generation assessed at the maximal down-regulation of the menstrual cycle (between the $5^{\text {th }}$ and $8^{\text {th }}$ day from the administration of the GnRH agonist) are predictors of IVF outcome. These tests could be used in the construction of a risk assessment model for IVF issue. The design of 
Table 3 Univariate analysis and odds ratio of thrombin generation test and the biomarkers of hypercoagulability for the positive IVF outcome

\begin{tabular}{|c|c|c|c|c|c|c|c|c|}
\hline \multirow[t]{2}{*}{ Variables } & \multicolumn{2}{|l|}{ T0 } & \multicolumn{2}{|l|}{$\mathrm{T} 1$} & \multicolumn{2}{|l|}{$\mathrm{T} 2$} & \multicolumn{2}{|l|}{ T3 } \\
\hline & $\begin{array}{l}\text { odds ratio } \\
\text { (95\% Conf. Interval) }\end{array}$ & $p$ & $\begin{array}{l}\text { odds ratio } \\
\text { (95\% Conf. Interval) }\end{array}$ & $p$ & $\begin{array}{l}\text { odds ratio } \\
\text { [95\% Conf. Interval) }\end{array}$ & $p$ & $\begin{array}{l}\text { odds ratio } \\
\text { (95\% Conf. Interval) }\end{array}$ & $p$ \\
\hline lag-time (min) & $\begin{array}{l}1.288 \\
(0.39-4.17)\end{array}$ & 0.672 & $\begin{array}{l}0.855 \\
(1.96-3.71)\end{array}$ & 0.835 & $\begin{array}{l}1.583 \\
(0.54-4.64)\end{array}$ & 0.403 & $\begin{array}{l}2.564 \\
(0.11-54.54)\end{array}$ & 0.56 \\
\hline ETP (nM.min) & $\begin{array}{l}0.999 \\
(0.99-1.00)\end{array}$ & 0.936 & $\begin{array}{l}1.002 \\
(1.00-1.00)\end{array}$ & $0.047^{*}$ & $\begin{array}{l}1.002 \\
(1.00-1.003)\end{array}$ & $0.016^{*}$ & $\begin{array}{l}1.000 \\
(0.99-1.00)\end{array}$ & 0.625 \\
\hline Peak (nM) & $\begin{array}{l}0.999 \\
(0.6-2.2)\end{array}$ & 0.974 & $\begin{array}{l}1.013 \\
(1.00-1.02)\end{array}$ & $0.006^{*}$ & $\begin{array}{l}1.018 \\
(1.01-1.03)\end{array}$ & $0.004^{*}$ & $\begin{array}{l}1.001 \\
(0.98-1.02)\end{array}$ & 0.952 \\
\hline ttPeak (min) & $\begin{array}{l}1.148 \\
(0.59-2.23)\end{array}$ & 0.684 & $\begin{array}{l}0.529 \\
(0.13-2.16)\end{array}$ & 0.375 & $\begin{array}{l}1.034 \\
(0.40-2.66)\end{array}$ & 0.945 & $\begin{array}{l}1.944 \\
(0.42-8.93)\end{array}$ & 0.394 \\
\hline MRI (nM/min) & $\begin{array}{l}0.997 \\
(0.98-1.01)\end{array}$ & 0.792 & $\begin{array}{l}1.032 \\
(1.01-1.05)\end{array}$ & $0.003^{*}$ & $\begin{array}{l}1.037 \\
(1.01-1.06)\end{array}$ & $0.005^{*}$ & $\begin{array}{l}0.993 \\
(0.96-1.02)\end{array}$ & 0.715 \\
\hline Procoag-PPL (sec) & $\begin{array}{l}1.009 \\
(0.88-1.15)\end{array}$ & 0.895 & $\begin{array}{l}1.399 \\
(1.07-1.82)\end{array}$ & $0.013^{*}$ & $\begin{array}{l}1.421 \\
(1.08-1.86)\end{array}$ & $0.011^{*}$ & $\begin{array}{l}1.112 \\
(0.91-1.33)\end{array}$ & 0.32 \\
\hline TFa (pM) & $\begin{array}{l}0.329 \\
(0.04-2.96)\end{array}$ & 0.322 & $\begin{array}{l}0.0022 \\
(0-0.21)\end{array}$ & $0.009^{*}$ & $\begin{array}{l}4.60 \mathrm{e}-08 \\
(2.14 \mathrm{e}-13.00)\end{array}$ & $0.007^{*}$ & $\begin{array}{l}1.141 \\
(1.03-1.27)\end{array}$ & 0.009 \\
\hline TMa (\%) & $\begin{array}{l}0.997 \\
(0.99-1.00)\end{array}$ & 0.598 & $\begin{array}{l}0.987 \\
(0.96-1.01)\end{array}$ & 0.223 & $\begin{array}{l}0.977 \\
(0.95-1.00)\end{array}$ & 0.107 & $\begin{array}{l}0.993 \\
(0.96-1.01)\end{array}$ & 0.368 \\
\hline FVIII (\%) & $\begin{array}{l}1.003 \\
(0.97-1.02)\end{array}$ & & $\begin{array}{l}1.004 \\
(0.97-1.03)\end{array}$ & 0.799 & $\begin{array}{l}1.028 \\
(0.99-1.06)\end{array}$ & 0.137 & $\begin{array}{l}1.143 \\
(0.97-1.34)\end{array}$ & 0.119 \\
\hline WWF (\%) & $\begin{array}{l}1.052 \\
(1.01-1.08)\end{array}$ & $0.004^{*}$ & $\begin{array}{l}1.009 \\
(0.98-1.04)\end{array}$ & 0.578 & $\begin{array}{l}1.012 \\
(0.07-1.05)\end{array}$ & 0.581 & $\begin{array}{l}1.062 \\
(0.97-1.16)\end{array}$ & 0.166 \\
\hline Fibrinogen (g/L) & $\begin{array}{l}1.228 \\
(0.48-3.16)\end{array}$ & 0.67 & $\begin{array}{l}0.979 \\
(0.18-5.16)\end{array}$ & 0.981 & $\begin{array}{l}2.014 \\
(0.31-13)\end{array}$ & 0.465 & $\begin{array}{l}6.346 \\
(0.63-63.38)\end{array}$ & 0.116 \\
\hline D-Dimers $(\mu \mathrm{g} / \mathrm{ml})$ & $\begin{array}{l}0.997 \\
(0.99-1.00)\end{array}$ & 0.408 & $\begin{array}{l}1 \\
(0.99-1.00)\end{array}$ & 0.951 & $\begin{array}{l}0.992 \\
(0.98-0.99)\end{array}$ & $0.016^{*}$ & $\begin{array}{l}1.243 \\
(0.82-1.45)\end{array}$ & 0.234 \\
\hline
\end{tabular}

the present study does not allow the identification of the underlying causes that lead to cellular activation and hypercoagulability which is observed at baseline. This investigation appears to be attractive for the elucidation of the link with hypercoagulability in women eligible for IVF. The association between hypercoagulablity and negative IVF outcome has recently been reported by Di

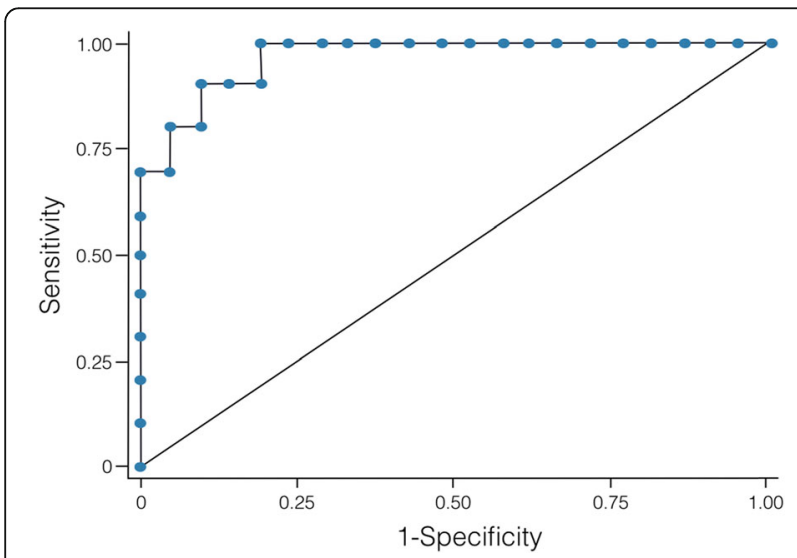

Fig. 1 The ROC analysis of the prediction model of the IVF outcome based on the MRI and Procoag-PPL. The AUC is 0.9667
Nisio et al., who proposed that the increase of D-Dimers levels in plasma is a predictor for IVF failure [35]. The implication of increased D-Dimers in the sterility is further supported by the data presented by Di Micco et al. [36]. The univariate analysis of the data reported herein confirms that the increase of D-Dimers during hormone treatment is a negative prognostic factor for IVF outcome. However, the impact of D-Dimers disappeared in the multivariate analysis indicating that high concentrations of procoagulant phospholipids, detected by the short Procoag-PPL, have a dominant role in negative IVF outcome.

Interestingly, increased thrombin generation was found to be a positive predictor for IVF outcome. This finding is in accordance with the concept that thrombin generation is necessary for blastocyst implantation, remodeling of decidualized human endometrial stromal cells and subsequent trophoblast invasion and remodeling of the spiral arteries and arterioles; a process driven by TF expression in the endometrial microenvironment which is in contact with mother's blood [7-10]. The concept that the non-suffering of endothelial cells, platelets or other cells that potentially release procoagulant phospholipids, is determinant for a positive IVF outcome is supported by our study. Indeed, the presence of high levels of procoagulant phospholipids 
in plasma, as expressed by shortened Procoag-PPL was the dominant parameter related with IVF failure while the decrease of thrombin generation was found to be a complementary factor. Control measurements showed that factor $\mathrm{V}$ and factor II levels were within the normal range (data not shown) ruling out clotting factors' consumption. The reasons for which thrombin generation is decreased in women with IVF failure have to be investigated.

At all studied time points the parameters of thromboelastometry were not significantly different between the IVF-group and the control group. Fibrinogen levels, platelet count and hematocrit are variables with a major impact on thromboelastometric profile. Both IVF-group and the control group had these variables within the normal ranges.

We found that when the ovarian stimulation was maximal, thrombin generation, FVIII, FvW and D-Dimers levels were significantly increased, in agreement with older studies [5, 37-41]. However, these changes were not reflected on the kinetics of clot formation and its qualitative characteristics when coagulation was triggered by a low TF concentration. In women undergoing hormone treatment for IVF preparation thromboelastographic analysis performed after triggering contact system showed a slight but significant acceleration of the kinetics of clot formation following $\mathrm{GnRH}$ treatment indicating that peak concentrations of estrogens are associated with a possible enhancement of FXII activation [42]. Women who had baseline thrombin generation above the UNL remained at the same levels during the down-regulation and the stimulation phase of the treatment (data not shown). Therefore, our data, in agreement with previous studies [43] and support the concept that hormone treatment for IVF represents a mild procoagulant stimulus, which has a minor effect on the global haemostatic balance, the kinetics of clot formation or its qualitative characteristics. Two weeks after hCG injection and embryo transfer, thrombin generation, TMa, TFa and Procoag-PPL remained without any significant modifications as compared to the phase of ovarian hyperstimulation. In contrast, the D-Dimers tended to increase and this finding is in agreement with others [2]. De Nisio et al., found that one week after the administration of gonadotropin, D-Dimers levels increased considerably [35]. We also found that even two weeks after GnRH injection D-Dimers levels are still increased, reflecting enhanced fibrin formation or fibrinolysis following $\mathrm{r}$-hCG, as described by Biron et al. [2].

The present study has some limitations. The number of the enrolled women, although it provides sufficient statistical power to identify the most relevant biomarkers related with IVF outcome, does not allow generalizability of the model. The group of IVF women was heterogeneous regarding the IVF indication. In some women the indication of the IVF was of male origin. Although the elimination of these cases did not significantly influence the final results, this does not warrant that the presence of this subpopulation had no impact on the results. A new prospective study in a larger population is planned to corroborate these findings. Women enrolled in the study were treated with three different protocols for estrogen down-regulation. The subgroup analysis according to the therapeutic protocol did not demonstrate any significant difference on the studied biomarkers among the subgroups (data not shown). Several different hormone treatments and protocols are applied for IVF preparation by the different IVF centers. Whether this protocol variability influences the kinetics of the studied biomarkers has to be investigated. However, the major findings of our study, which are (a) the presence of cell derived hypercoagulable state at the baseline, before any treatment administration and (b) the predictive value of the ProcoagPPL clotting time associated with the MRI of thrombin generation on IVF outcome are not influenced by the subsequent hormone treatments for ovarian stimulation. Although this study fulfils the criteria for the statistical power in the selection of the most clinically relevant biomarkers, a new prospective independent validation of this model is required in a larger multicenter study.

It has been suggested that heparin may improve the intrauterine environment in sub-fertile women, by enhancing growth factors to improve attachment of the embryo to the lining of the womb [44]. Thus low molecular weight heparin (LMWH) is often offered to women eligible for IVF as an adjunct treatment in an attempt to improve the probability for a positive outcome. However, a recent metaanalysis showed that it is unclear whether peri-implantation heparin administration in assisted reproduction treatment cycles improves clinical pregnancy rates in sub-fertile women [45]. The elaboration of a risk assessment model with the clinically relevant biomarkers of hypercoagulability proposed by the present study is of clinical interest in order to identify women who could benefit from the periimplantation administration of antithrombotic treatment.

\section{Conclusions}

The data presented herein show that hypercoagulability of cellular origin is the dominant biological process related with IVF failure. Hypercoagulabilty of cellular origin appears at the baseline, before any hormone treatment administration and it is not modified by this treatment. The administration of hormone treatment during the IVF preparation does not lead to substantial alteration of global coagulation process. Among the large variety of the studied biomarkers, the evaluation of both Procoag-PPL and MRI of thrombin generation after down-regulation of the menstrual cycle appear to be the most clinically relevant biomarkers for the identification of the women at risk of IVF failure. 


\section{Abbreviations}

AUC: Area under the curve; BMI: Body mass index; CAT: Calibrated Automated Thrombogram; CFT: Clot formation time; CT: Clotting time; E2: Estradiol; ETP: Endogenous thrombin potential; FSH: Follicular stimulating hormone; FVIII: Factor VIII; FvW: Factor von Willebrand; GnRH: Gonadotropin-releasing hormone agonist; hCG: Human recombinant chorion gonadotropin; IVF: In vitro fertilization; LNL: Lower Normal Limit; MCF: Maximum clot firmness; min TF-WB TEM: Minimal TF-triggered whole blood thromboelastometry; MRI: Mean rate index; PA1-1: Plasminogen activator inhibitor 1; PPP: Platelet poor plasma; Procoag-PPL: Procoagulant phospholipid clotting time; ROC: Receiver operating characteristics; TAFI: Thrombin activatable fibrinolysis inhibitor; TFa: Tissue factor activity; TFPI: Tissue factor pathway inhibitor; TG: Thrombin generation; TMa: Thrombomodulin activity; ttPeak: Time to Peak; UNL: Upper Normal Limit; VTE: Venous thromboembolism

\section{Acknowledgements}

The authors acknowledge the nurses from the Department of Obstetrics and Gynecology for their efforts to collect blood samples. The authors wish to thank the skilful technical assistance of the technicians of the Laboratory of Haemostasis, Service d'Hématologie Biologique, Hôpital Tenon and particularly Mme Marie Paule Roman and Severine Bouffard.

\section{Funding}

The study was supported by the Association de Recherche sur la Thrombose et l'Évaluation de son Risque (ARTER) and by an unrestricted grant by Diagnostica Stago.

\section{Availability of data and materials}

The datasets generated during and/or analyzed during the current study are available from the corresponding author on reasonable request.

\section{Authors' contributions}

GTG has made substantial contributions to conception and design of the study, analysis and interpretation of data, has been involved in drafting the manuscript has given final approval of the version to be published, agreed to be accountable for all aspects of the work in ensuring that questions related to the accuracy or integrity of any part of the work are appropriately investigated and resolved. PVD has made substantial contributions to study design and organization, acquisition, analysis and interpretation of data, has been involved in drafting the manuscript. EMD has made substantial contribution to the design of the study, the selection of the patients and the interpretation of the data, EL has made substantial contribution in the interpretation of the data, the writing and editing of the paper. MG: was responsible for the technical party. MC: was responsible for patients' recruitment. RS: was responsible of statistical analysis, interpretation of the data. HK: was responsible for data collection. AKL was responsible for critical revision of the article for important intellectual content. IE critically reviewed the manuscript. All authors read and approved the final manuscript.

\section{Competing interests}

The authors declare that they have no competing interests.

\section{Consent for publication}

Written informed consent for publication of clinical details and/or images was obtained from the patients.

\section{Ethics approval and consent to participate}

The ethics committee of the Hôpitaux Universitaires Est Parisien, Assistance Publique Hôpitaux de Paris, France (Comité de Protection des Personnes lle-deFrance $V$ approved the study protocol (approval no. 234/2013). The patients gave informed consent to participate.

\section{Capsule}

Women eligible for IVF at baseline show hypercoagulability related with IVF failure. Hormone treatment does not enhance hypercoagulability. Shortened procoagulant phospholipid clotting time and mean rate index of thrombin generation are predictors for IVF failure.

\section{Publisher's Note}

Springer Nature remains neutral with regard to jurisdictional claims in published maps and institutional affiliations.

\section{Author details}

'Cancer Biology and Therapeutics, Centre de Recherche Saint-Antoine, Institut National de la Santé et de la Recherche Médicale (INSERM) U938 and Université Pierre et Marie Curie (UPMC), Sorbonne Universities, Paris, France. ${ }^{2}$ Service d'Hématologie Biologique, Hôpital Tenon, Hôpitaux Universitaires Est Parisien, Assistance Publique Hôpitaux de Paris, 4, rue de la Chine, Paris Cedex 20, France. ${ }^{3}$ Clinical Research Department, Diagnostica Stago, Gennevilliers, France. ${ }^{4}$ Department of Obstetrics and Gynecology, Hôpital Tenon, Hôpitaux Universitaires Est Parisien, Assistance Publique Hôpitaux de Paris, Paris, France.

Received: 29 December 2016 Accepted: 6 March 2017

Published online: 28 March 2017

\section{References}

1. Andersson $\mathrm{O}$, Blomback M, Bremme $\mathrm{K}$, et al. Prediction of changes in levels of haemostatic variables during natural menstrual cycle and ovarian hyperstimulation. Thromb Haemost. 1997;77:901-4.

2. Biron C, Galtier-Dereure F, Rabesandratana H, et al. Hemostasis parameters during ovarian stimulation for in vitro fertilization: results of a prospective study. Fertil Steril. 1997;67:104-9.

3. Aune B, Høie KE, Oian P, Holst N, Osterud B. Does ovarian stimulation for in-vitro fertilization induce a hypercoagulable state? Hum Reprod. 1991;6:925-7.

4. Brummel-Ziedins KE, Gissel M, Francis $C$, et al. The effect of high circulating estradiol levels on thrombin generation during in vitro fertilization. Thromb Res. 2009;124:505-7.

5. Westerlund $\mathrm{E}$, Henriksson $\mathrm{P}$, Wallén $\mathrm{H}$, et al. Detection of a procoagulable state during controlled ovarian hyperstimulation for in vitro fertilization with global assays of haemostasis. Thromb Res. 2012;130:649-53.

6. Chighizola CB, de Jesus GR. Antiphospholipid antibodies and infertility. Lupus. 2014;23:1232-8.

7. Girardi G. Role of tissue factor in feto-maternal development: a xiphos. J Thromb Haemost. 2011;9:250-6.

8. Lockwood CJ, Paidas M, Murk WK, et al. Involvement of human decidual cell-expressed tissue factor in uterine hemostasis and abruption. Thromb Res. 2009;124:516-20.

9. Krikun G, Lockwood CJ, Paidas MJ. Tissue factor and the endometrium: from physiology to pathology. Thromb Res. 2009;124:393-6.

10. Lockwood CJ, Krikun G, Caze R, et al. Decidual cell-expressed tissue factor in human pregnancy and its involvement in hemostasis and preeclampsiarelated angiogenesis. Ann N Y Acad Sci. 2008;1127:67-72.

11. Gupta S, Agarwal A, Sharma RK. The role of placental oxidative stress and lipid peroxidation in preeclampsia. Obstet Gynecol Surv. 2005;60:807-16.

12. Spronk HM, Dielis AW, De Smedt E, et al. Assessment of thrombin generation II: validation of the calibrated automated thrombogram in platelet-poor plasma in a clinical laboratory. Thromb Haemost. 2008;100:362-4.

13. Hemker HC, Willems GM, Beguin S. A computer assisted method to obtain the propthrombin activation velocity in whole plasma independent of thrombin decay processes. Thromb Haemost. 1986;56:9-17.

14. Chakroun T, Gerotziafas GT, Seghatchian J, et al. The influence of fibrin polymerization and platelet-mediated contractile forces on citrated whole blood thromboelastography profile. Thromb Haemost. 2006;95:822-8.

15. Chaari M, Ayadi I, Rousseau A, et al. Impact of breast cancer stage, time from diagnosis and chemotherapy on plasma and cellular biomarkers of hypercoagulability. BMC Cancer. 2014;22(14):991-1004.

16. Gerotziafas GT, Van Dreden P, Chaari M, et al. The acceleration of the propagation phase of thrombin generation in patients with sickle cell disease is associated with circulating erythrocyte-derived microparticles. Thromb Haemost. 2012;107:1044-52.

17. Gerotziafas GT, Depasse F, Busson J, et al. Towards a standardization of thrombin generation assessment: the influence of tissue factor, platelets and phospholipids concentration on the normal values of ThrombogramThrombinoscope assay. Thromb J. 2005;3:16-27.

18. Konstantinidis K, Gerasimidis T, Verdy E, et al. Inhibition of clot formation process by treatment with the low-molecular-weight heparin nadroparin in patients with carotid artery disease undergoing angioplasty and stenting. A thromboelastography study on whole blood. Thromb Haemost. 2007;97:109-18.

19. Rousseau A, Favier R, Van Dreden P. Elevated circulating soluble thrombomodulin activity, tissue factor activity and circulating procoagulant phospholipids: new and useful markers for pre-eclampsia? Eur J Obstet Gynecol Reprod Biol. 2009;146:46-9. 
20. Van Dreden P, Rousseau A, Savoure A, et al. Plasma thrombomodulin activity, tissue factor activity and high levels of circulating procoagulant phospholipid as prognostic factors for acute myocardial infarction. Blood Coagul Fibrinolysis. 2009;220:635-41.

21. Schneider P, Van Dreden P, Rousseau A, et al. M. Increased levels of tissue factor activity and procoagulant phospholipids during treatment of children with acute lymphoblastic leukaemia. Br J Haematol. 2010;148:582-92.

22. Patil R, Ghosh K, Satoskar P, et al. Elevated procoagulant endothelial and tissue factor expressing microparticles in women with recurrent pregnancy loss. PLoS One. 2013;8:e81407.

23. Patil R, Ghosh K, Shetty S. A simple clot based assay for the detection of procoagulant cell-derived microparticles. Clin Chem Lab Med. 2016;54:799-803.

24. Ohlin AK, Larsson K, Hansson M. Soluble thrombomodulin activity and soluble thrombomodulin antigen in plasma. J Thromb Haemost. 2005;3:976-82.

25. Boffa MC. Considering cellular thrombomodulin distribution and its modulating factors can facilitate the use of plasma thrombomodulin as a reliable endothelial marker. Haemostasis. 1996;26:233-43.

26. Iann A, Seigneur M. Soluble markers of endothelial cell function. Clin Hemorheol Microcirc. 1997:17:3.

27. Slavik L, Novak M, Ulehlova J, Prochazka M, Prochazkova J, Lattova V, Polak P, Pilka R. Possibility of coagulation system activation determination with tissue factor in pregnancy complications. Clin Lab. 2016;62:1851-6.

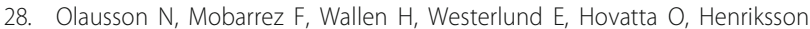
P. Microparticles reveal cell activation during IVF - a possible early marker of a prothrombotic state during the first trimester. Thromb Haemost. 2016;116:517-23.

29. Martínez-Zamora MA, Creus M, Tassies D, Reverter JC, Civico S, Carmona F, et al. Reduced plasma fibrinolytic potential in patients with recurrent implantation failure after IVF and embryo transfer. Hum Reprod. 2011;26:510-6.

30. Sarto A, Rocha M, Martínez M, Sergio Pasqualini R. Hypofibrinolysis and other hemostatic defects in women with antecedents of early reproductive failure. Medicina (B Aires). 2000;60:441-7.

31. Romagnuolo I, Sticchi E, Fedi S, Cellai AP, Lami D, Alessandrello Liotta A, Rogolino A, Cioni G, Noci I, Abbate R, Fatini C. Is tissue factor pathway inhibitor a marker of procoagulable status in healthy infertile women undergoing ovarian stimulation for assisted reproduction? Blood Coagul Fibrinolysis. 2014;25:254-8.

32. Altmäe S, Salumets A, Bjuresten K, Kallak TK, Wånggren K, Landgren BM, Hovatta O, Stavreus-Evers A. Tissue factor and tissue factor pathway inhibitors TFPI and TFPI2 in human secretory endometrium-possible link to female infertility. Reprod Sci. 2011;18:666-78.

33. Alijotas-Reig J, Ferrer-Oliveras R, Ruffatti A, Tincani A, Lefkou E, Bertero MT, Coloma-Bazan E, de Carolis S, Espinosa G, Rovere-Querini P, Kuzenko A Valverde EE, Robles A, Cervera R, Canti V, Fredi M, Gil-Aguado A, Lundelin K, Llurba E, Melnychuk T, Nalli C, Picardo E, Silvestro E, del Ross T, Farran-Codina I, EUROAPS Study Group Collaborators. Autoimmun Rev. 2015;14:387-9.

34. La Farina F, Raparelli V, Napoleone L, Guadagni F, Basili S, Ferroni P. Inflammation and thrombophilia in pregnancy complications: implications for risk assessment and clinical management. Cardiovasc Hematol Disord Drug Targets. 2016;15:187-203.

35. Di Nisio M, Porreca E, Di Donato V, et al. Plasma concentrations of D-dimer and outcome of in vitro fertilization. J Ovarian Res. 2014;22:58-62.

36. Di Micco P, D'Uva M, Strina I, Mollo A, Amato V, Niglio A, De Placido G. The role of $\mathrm{d}$-dimer as first marker of thrombophilia in women affected by sterility: implications in pathophysiology and diagnosis of thrombophilia induced sterility. J Transl Med. 2004;2:38.

37. Lox C, Cañez M, Deleon F, et al. Hyperestrogenism induced by menotropins alone or in conjunction with luprolide acetate in in vitro fertilization cycles: the impact on hemostasis. Fertil Steril. 1995;63:566-70.

38. Harnett MJ, Bhavani-Shankar K, Datta S, et al. In vitro fertilization-induced alterations in coagulation and fibrinolysis as measured by thromboelastography. Anesth Analg. 2002;95:1063-6.

39. Winkler U, Bühler K, Koslowski S, et al. Plasmatic haemostasis in gonadotrophin-releasing hormone analogue therapy: effects of leuprorelin acetate depot on coagulatory and fibrinolytic activities. Clin Ther. 1992; 14(Suppl A):114-20.

40. Westerlund E, Antovic A, Hovatta O, et al. Changes in von Willebrand factor and ADAMTS13 during IVF. Blood Coagul Fibrinolysis. 2011;22:127-31.

41. Richard-Davis G, Montgomery-Rice V, Mammen EF, Alshameeri RS, Morgan D, Moghissi KS. In vitro platelet function in controlled ovarian hyperstimulation cycles. Fertil Steril. 1997;67:923-7.
42. Orbach-Zinger S, Eidelman LA, Lutsker A, Oron G, Fisch B, Ben-Haroush A. The effect of in vitro fertilization on coagulation parameters as measured by thromboelastogram. Eur J Obstet Gynecol Reprod Biol. 2016;201:118-20.

43. Curvers J, Nap AW, Thomassen MC, Nienhuis SJ, Hamulyák K, Evers JL, Tans $\mathrm{G}$, Rosing J. Effect of in vitro fertilization treatment and subsequent pregnancy on the protein C pathway. Br J Haematol. 2001;115:400-7.

44. Fluhr H, Spratte J, Ehrhardt J, et al. Heparin and low-molecular-weight heparins modulate the decidualization of human endometrial stromal cells. Fertil Steril. 2010:93:2581-7.

45. Akhtar MA, Sur S, Raine-Fenning N, et al. Heparin for assisted reproduction. Cochrane Database Syst Rev. 2013;8, CD009452. doi:10.1002/14651858. CD009452.

\section{Submit your next manuscript to BioMed Central and we will help you at every step:}

- We accept pre-submission inquiries

- Our selector tool helps you to find the most relevant journal

- We provide round the clock customer support

- Convenient online submission

- Thorough peer review

- Inclusion in PubMed and all major indexing services

- Maximum visibility for your research

Submit your manuscript at www.biomedcentral.com/submit
C Biomed Central 